\section{Case Reports in Ophthalmology}

Case Rep Ophthalmol 2016;7:398-403

DOI: $10.1159 / 000448164$

Publisnea oninne. september 7, 2016
(C) 2016 The Author(s)

Published by S. Karger AG, Basel www.karger.com/cop

This article is licensed under the Creative Commons Attribution-NonCommercial 4.0 International License (CC BY-NC) (http://www.karger.com/Services/OpenAccessLicense). Usage and distribution for commercial purposes requires written permission.

\title{
Solitary Fibrous Tumor in the Lacrimal Gland Fossa: A Case Report
}

\author{
Jacqueline Mupas-Uy ${ }^{a} \quad$ Yoshiyuki Kitaguchi $^{a} \quad$ Yasuhiro Takahashi $^{\mathrm{a}}$ \\ Emiko Takahashi ${ }^{\text {b }}$ Hirohiko Kakizaki ${ }^{a}$ \\ a Department of Oculoplastic, Orbital and Lacrimal Surgery, Aichi Medical University \\ Hospital, Aichi, Japan; ${ }^{b}$ Department of Pathology, Aichi Medical University Hospital, \\ Aichi, Japan
}

\section{Keywords}

Solitary fibrous tumor $\cdot$ Lacrimal gland fossa $\cdot$ Young $\cdot$ Immunohistochemical

\begin{abstract}
Solitary fibrous tumors (SFTs) are benign, spindle-cell tumors of mesenchymal origin that are usually seen in the superior orbital area in adults. We report a rare case of SFT in the lacrimal gland fossa that developed in a young female. A 25-year-old woman had a 6-month history of a progressive painless mass in the left upper eyelid accompanied by proptosis. Computed tomography and magnetic resonance imaging showed an ovoid, demarcated mass with distinct margins in the lacrimal gland region without bone invasion. Excision biopsy with immunohistochemical study, specifically with positive signal transducer and activator of transcription 6, confirmed the diagnosis.

(C) 2016 The Author(s) Published by S. Karger AG, Basel
\end{abstract}

\section{Introduction}

Solitary fibrous tumors (SFTs) are rare, benign, spindle-cell tumors of mesenchymal origin that generally develop in adults. SFTs of the orbit have been diagnosed with increasing frequency in recent years as the result of widespread use of immunohistochemistry, although rare. SFTs arise in many locations of the orbital soft tissues, but commonly involve the superior area [1]. Since Scott et al. [2] first reported SFT in the lacrimal gland fossa in 
1996, there have only been 9 reported cases in the lacrimal gland fossa (table 1) [1-7]. We report a case of SFT in the lacrimal gland fossa presenting at a young age, including features of imaging, histological and immunohistochemical studies.

\section{Case Report}

A 25-year-old woman presented with a painless palpable mass in the left upper eyelid accompanied by mild proptosis (fig. 1). The mass was mobile, hard, smooth, nontender and well delineated. It increased in size for 6 months, reaching approximately $15 \mathrm{~mm}$ in diameter. Computed tomography showed a homogenous isodense ovoid mass with distinct margins without bone invasion in the lacrimal gland fossa (fig. 2). T1- and T2-weighted magnetic resonance imaging showed a high-intensity mass with various low-intensity areas, encapsulated by a low-intensity 1-mm thick capsule (fig. 2). The preoperative diagnosis was lacrimal gland tumor or deep dermoid cyst.

The patient underwent tumor excision via upper eyelid crease approach. A smooth, encapsulated mass was identified beneath the swollen lacrimal gland (fig. 3). The tumor was not attached to the periosteum and was completely removed. Postoperatively, there was noted improvement of proptosis. At the time of last examination, 6 months after surgery, no evidence of recurrence was observed.

Postoperative histopathology revealed bipolar oval to spindle-shaped cells in a heavily collagenized stroma, with focal accumulation of macrophages (fig. 4a, b). No necrosis was present. Immunohistochemical findings supported the diagnosis of SFT. Tumor cells were positive for the cluster of differentiation 34 (CD34), signal transducer and activator of transcription 6 (STAT6), S-100, B-cell leukemia-2 (BCL-2), CD99 and $\alpha$-smooth muscle actin (SMA), but negative for desmin, epithelial membrane antigen (EMA) and cytokeratin (fig. 4c, d). MIB-1 was present in $10 \%$ of all cells.

\section{Discussion}

We present the rare case of a 25-year-old woman with orbital SFT in the lacrimal gland fossa. The lacrimal gland ducts and acini are of epithelial origin, but not the main/palpebral lobes of the lacrimal gland. SFT therefore likely arises from periductal connective tissue or from other mesenchymal elements in the lacrimal gland fossa, with subsequent tumor growth around the lacrimal gland ducts and acini [2]. There is no apparent gender predilection for this tumor.

Orbital SFT rarely occurs at a young age [3], but generally develops in the fifth to seventh decade of life. SFT in the lacrimal gland fossa has a preponderance in the third decade of life, including this case (table 1). SFT must therefore be considered in lacrimal gland fossa tumors presenting in young adults.

The clinical presentation of orbital SFT in the lacrimal gland fossa is similar to other lacrimal gland tumors with a slow-growing painless palpable mass, but less commonly with ptosis, eyelid swelling and diplopia (table 1). SFT must therefore be listed in the differential diagnoses for lacrimal gland tumors in the younger age group. Deep dermoids also comprise another differentiation with these symptoms and age [8].

The reported radiological appearances of SFT are nonspecific. This tumor usually shows a well-defined mass, which is isointense on T1-weighted images and isointense to hypo- 


\section{Case Reports in Ophthalmology}

intense on T2-weighted images, reflecting fibrous tissue with high collagen content. Hyperintense areas are occasionally seen within the lesion on T2-weighted images, as shown in the present case. Variations of the signal intensity on T2-weighted magnetic resonance images likely reflect differences in the amount of cellular components, collagen, and fibroblasts as well as in the extent of degenerative change contained in the individual tumors [9].

Histologically, SFTs are difficult to differentiate from other spindle cell tumors. In this case, the findings showed spindle-shaped cells in heavily collagenized stroma. Fibrous histiocytoma, hemangiopericytoma, and giant cell angiofibroma, however, also present in a similar fashion. Immunohistochemistry is needed to confirm the diagnosis of SFT.

Immunohistochemically, SFTs commonly show positivity for CD34 (80-90\% of cases), CD99 (70\%), BCL-2 (30\%), EMA (30\%) and SMA (20\%), but negativity for S-100, desmin and cytokeratin [10]. However, these markers are currently known to be nonspecific, resulting in many exceptions. For example, CD34, CD99, BCL-2 and SMA were positive, but S-100 was unusually positive in the present case. Since there were contradictory results for the aforementioned markers, further staining with STAT6 confirmed the definitive diagnosis. More recently, demonstration of strong nuclear expression of the C-terminal of STAT6 has been shown to be a highly sensitive and specific marker for SFT, with an aggregate sensitivity of $98 \%$ and a specificity $>85 \%$ [11].

Complete resection is the single most important determinant for the prognosis of SFTs. There is no conclusive evidence that radiotherapy or chemotherapy provide any benefits in cases of residual tumors. Hence, these tumors may need further surgical excision, and regular follow-up is essential. In this case, the encapsulated nature of the tumor allowed total excision, resulting in no recurrence following surgery.

Although rare, orbital SFTs show malignant progression [12]. Risk factors for a malignant potential include presence of histological malignant component, with increased cellularity and mitoses, positive surgical margins, and tumor size $>10 \mathrm{~cm}$ [13]. No histological malignancy, total excision, and tumor size $<10 \mathrm{~cm}$ in this patient were associated with little risk of future recurrence with malignant progression.

In summary, SFT must be considered in lacrimal gland fossa tumors presenting in young adults. They are rare tumors of mesenchymal origin for which positive staining for STAT6 is the most specific diagnostic test. They generally follow a benign course and are treated definitively with surgical excision.

\section{Statement of Ethics}

This study was approved by the ethics committee of Aichi Medical University Hospital and adhered to the tenets of the 1964 Declaration of Helsinki. Written informed consent was obtained from the patient for publication of this case report and any accompanying images.

\section{Disclosure Statement}

The authors declare that they have no competing interests. 


\section{Case Reports in Ophthalmology}

\section{References}

1 Furusato E, Valenzuela IA, Fanburg-Smith JC, Auerbach A, Furusato B, Cameron JD, Rushing EJ: Orbital solitary fibrous tumor: encompassing terminology for hemangiopericytoma, giant cell angiofibroma, and fibrous histiocytoma of the orbit: reappraisal of 41 cases. Hum Pathol 2011;42:120-128.

-2 Scott IU, Tanenbaum M, Rubin D, Lares E: Solitary fibrous tumour of the lacrimal gland fossa. Ophthalmology 1996;103:1613-1618.

-3 Kim HY, Lee SY, Kang SJ, Kim HJ: Solitary fibrous tumor of the orbit: a poorly-recognized orbital lesion. Acta Ophthalmol Scand 1999;77:704-708.

4 Polito E, Tosi GM, Toti P, Schürfeld K, Caporossi A: Orbital solitary fibrous tumor with aggressive behaviour. Three cases and review of the literature. Graefes Arch Clin Exp Ophthalmol 2002;240:570574.

5 Bernardini FP, de Conciliis C, Schneider S, Kerstern RC, Kulwin DR: Solitary fibrous tumor of the orbit: is it rare? Report of a case series and review of the literature. Ophthalmology 2003;110:1442-1448.

-6 Son DH, Yoo SH, Sa H, Cho K: A solitary fibrous tumor with giant cells in the lacrimal gland: a case study. Korean J Pathol 2013;47:158-162.

7 Narang V, Singh N, Bajwa G, Sood N: Solitary fibrous tumour of lacrimal gland: a rare entity. J Clin Diagn Res 2015;9:3-4.

8 Mafee MF, Edward D, Koeller KK, Dorodi S: Lacrimal gland tumors and simulating lesions. Clinicopathologic and MR imaging features. Radiol Clin North Am 1999;37:219-239.

\9 Kim HJ, Kim HJ, Kim YD, Yim YJ, Kim ST, Jeon P, Kim KH, Byun HS, Song HJ: Solitary fibrous tumor of the orbit: CT and MR imaging findings. AJNR Am J Neuroradiol 2008;29:857-862.

10 Gengler C, Guillou L: Solitary fibrous tumour and haemangiopericytoma: evolution of a concept. Histopathology 2006;48:63-74.

11 Doyle LA, Vivero M, Fletcher CD, Mertens F, Hornick JL: Nuclear expression of STAT6 distinguishes solitary fibrous tumor from histologic mimics. Mod Pathol 2014;27:390-395.

12 Girnita L, Sahlin S, Orrego A, Seregard S: Malignant solitary fibrous tumour of the orbit. Acta Ophthalmol 2009;87:464-467.

13 Gold JS, Antonescu CR, Hajdu C, Ferrone CR, Hussain M, Lewis JJ, Brennan MF, Coit DG: Clinicopathologic correlates of solitary fibrous tumors. Cancer 2002;94:1057-1068.

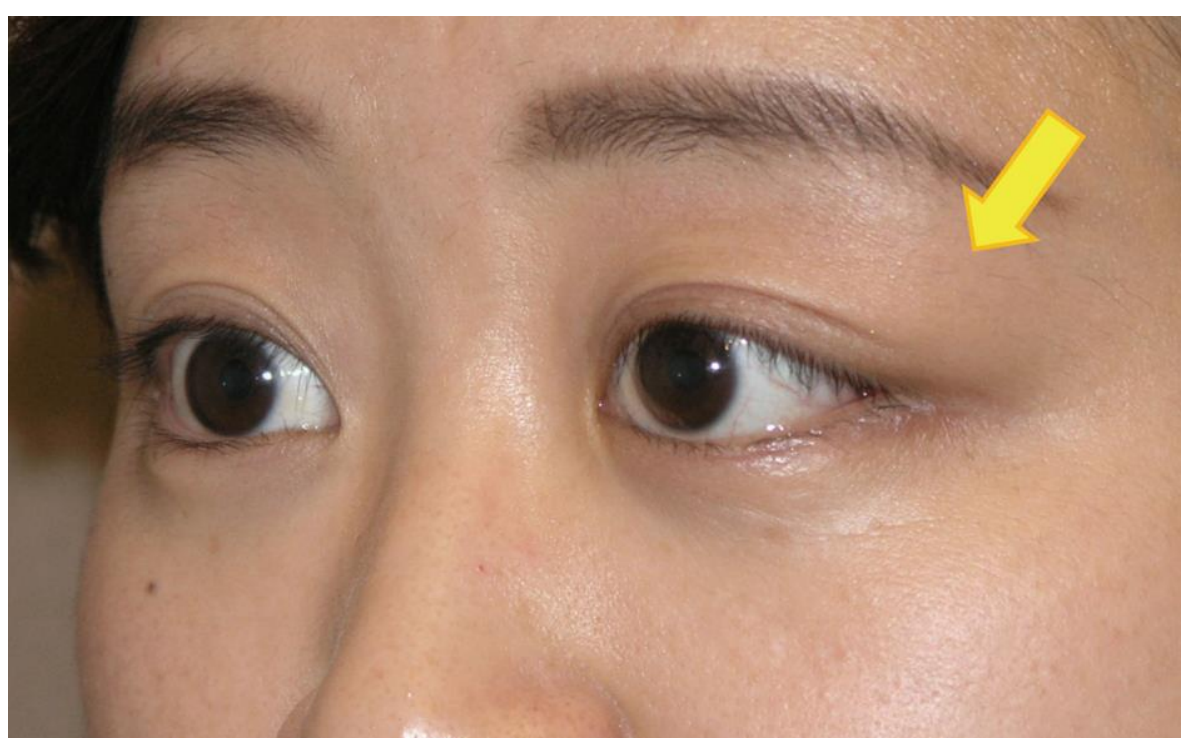

Fig. 1. Preoperative face photograph. A hard, smooth, well-delineated mass (15 $\mathrm{mm}$ in diameter) is shown (arrow). 


\section{Case Reports in Ophthalmology}

\begin{tabular}{l|l}
\hline Case Rep Ophthalmol 2016;7:398-403 \\
\hline DOI: 10.1159/000448164 & $\begin{array}{l}\text { ○ 2016 The Author(s). Published by S. Karger AG, Basel } \\
\text { www.karger.com/cop }\end{array}$ \\
\hline
\end{tabular}
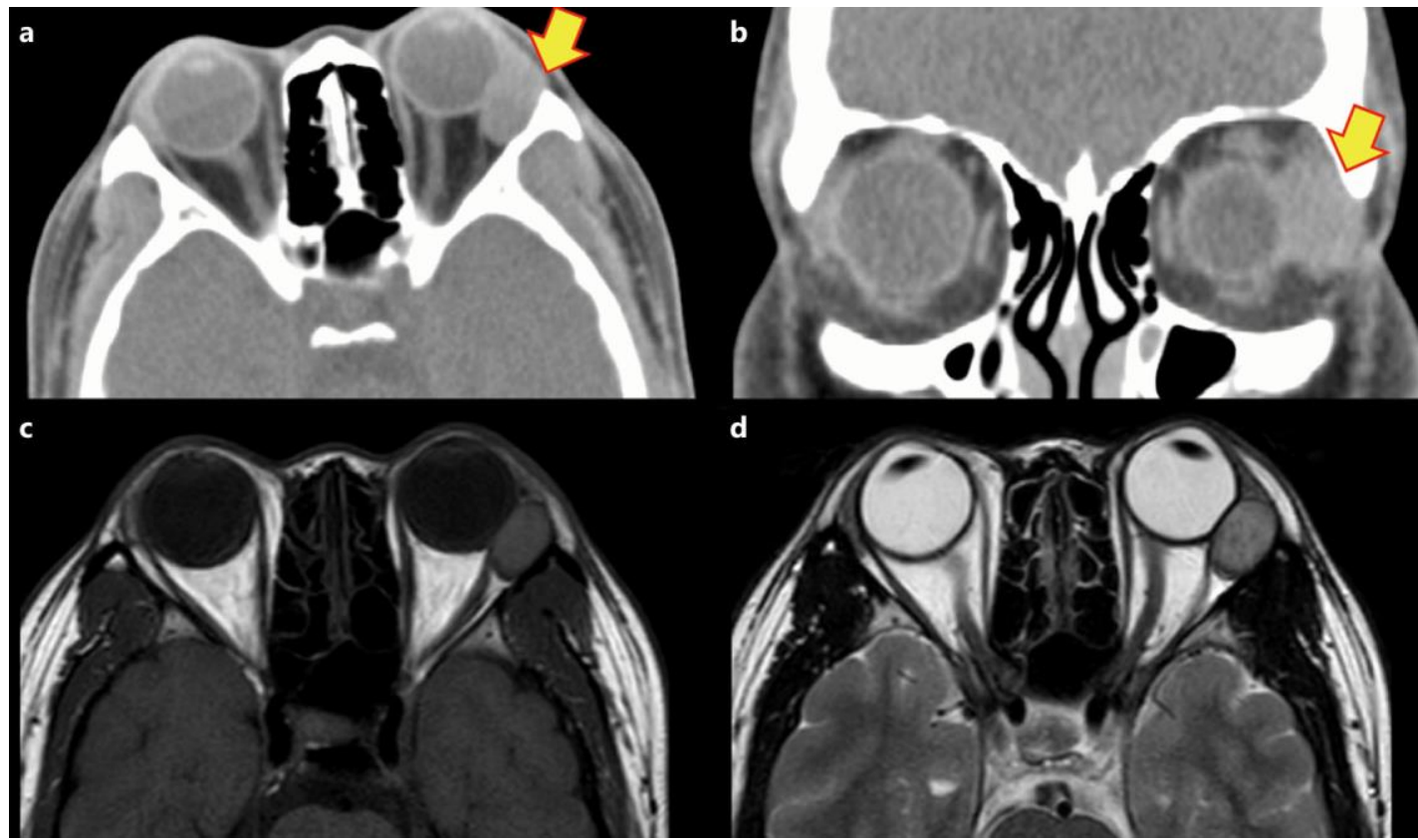

Fig. 2. Findings of imaging studies. a, b Computed tomography showed a homogenous isodense round to ovoid lesion with distinct margins without bone invasion in the extraconal superolateral orbit (arrows). c, d T1- and T2-weighted magnetic resonance imaging showed a high-intensity mass with contents of various intensity.

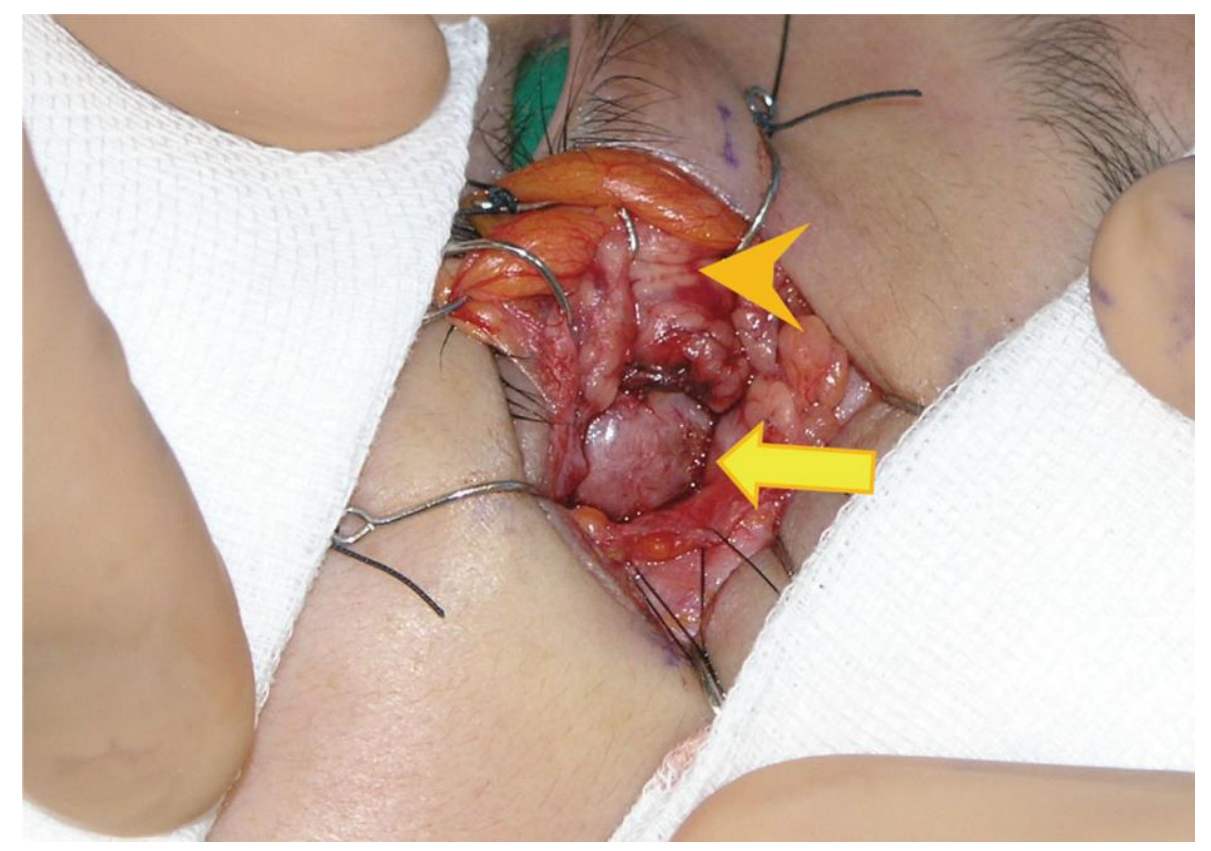

Fig. 3. Upper eyelid crease incision revealed a smooth, encapsulated mass (arrow) under a whitish, mildly swollen lacrimal gland (arrowhead). 


\section{Case Reports in Ophthalmology}
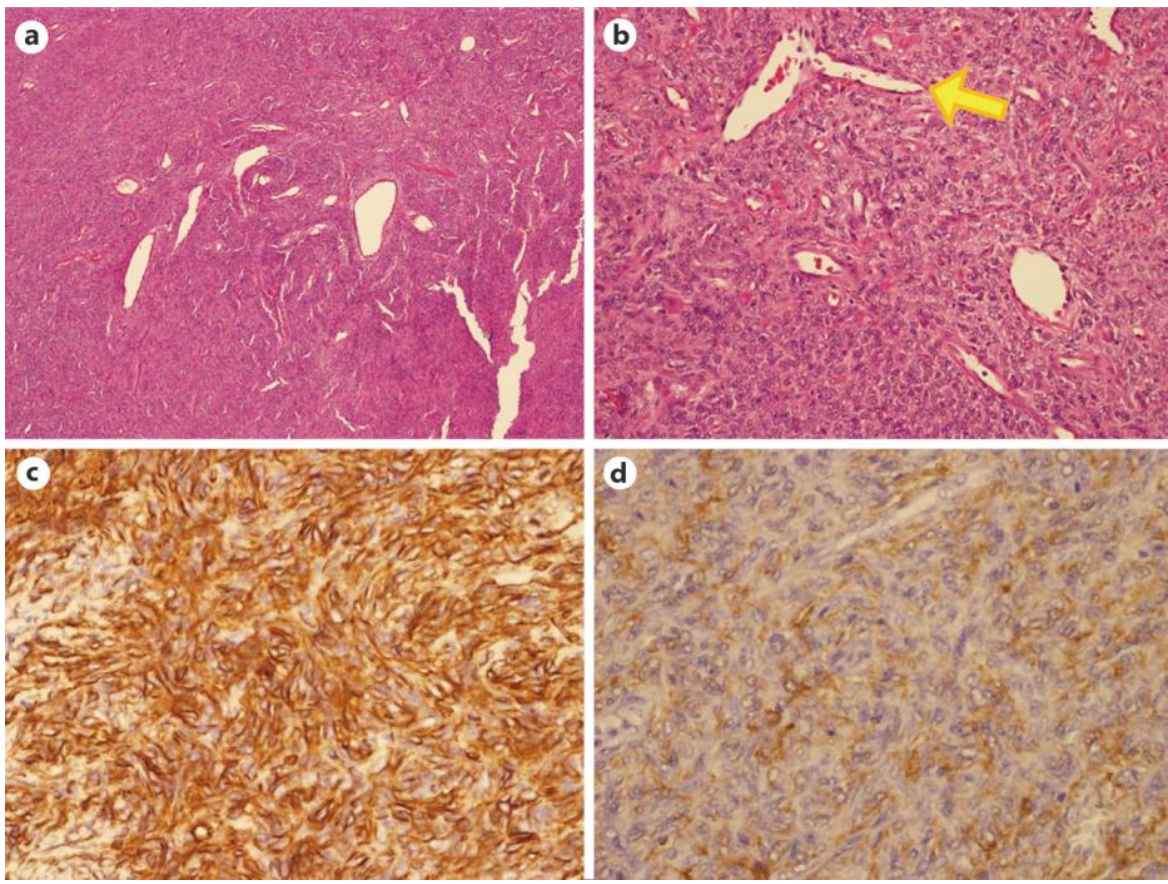

Fig. 4. Dispersion of oval to spindle-shaped cells in a heavily collagenized stroma with staghorn vessels (arrow), consistent with a SFT. a Hematoxylin and eosin, $\times 40$. b Hematoxylin and eosin, $\times 200$. c CD34 (original magnification $\times 400$ ). $d$ S-100 (original magnification $\times 400$ ).

Table 1. Clinical findings of SFT in the lacrimal fossa

\begin{tabular}{|c|c|c|c|c|}
\hline $\begin{array}{l}\text { Case } \\
\text { No. }\end{array}$ & $\begin{array}{l}\text { Age/ } \\
\text { sex }\end{array}$ & Clinical presentation & Follow-up & Reference \\
\hline 1 & $76 / \mathrm{M}$ & ptosis, proptosis & NED 1 year & Scott et al. [2], 1996 \\
\hline 2 & $24 / \mathrm{M}$ & $\begin{array}{l}\text { palpable mass, swelling, } \\
\text { proptosis }\end{array}$ & NED 21 months & Kim et al. [3], 1999 \\
\hline 3 & $26 / F$ & $\begin{array}{l}\text { palpable mass, swelling, } \\
\text { proptosis, diplopia, ptosis }\end{array}$ & NED 5 months & Kim et al. [3], 1999 \\
\hline 4 & $24 / \mathrm{M}$ & palpable mass & recurrence 4 years & Polito et al. [4], 2002 \\
\hline 5 & $37 / \mathrm{M}$ & proptosis & NED 3 months & Bernardini et al. [5], 2003 \\
\hline 6 & NA & NA & NA & Furusato et al. [1], 2011 \\
\hline 7 & NA & NA & NA & Furusato et al. [1], 2011 \\
\hline 8 & $39 / \mathrm{M}$ & palpable mass & NED & Son et al. [6], 2013 \\
\hline 9 & $50 / \mathrm{M}$ & palpable mass, swelling & NED & Narang et al. [7], 2015 \\
\hline 10 & $25 / F$ & palpable mass, proptosis & NED 6 months & current case \\
\hline
\end{tabular}

$\mathrm{NA}=$ Not available; NED = no evidence of disease 